\title{
Electrical characterization of defects introduced during electron beam deposition of W Schottky contacts on $n$-type $4 \mathrm{H}-\mathrm{SiC}$
}

\author{
E. Omotoso ${ }^{1,2,{ }^{*}}$, W.E. Meyer ${ }^{1}$, S.M.M. Coelho ${ }^{1}$, M. Diale ${ }^{1}$, P.N.M. Ngoepe ${ }^{1}$ and F.D. Auret ${ }^{1}$ \\ ${ }^{1}$ Department of Physics, University of Pretoria, Private Bag X20, Hatfield 0028, South Africa \\ ${ }^{2}$ Departments of Physics, Obafemi Awolowo University, Ile-Ife, 220005, Nigeria \\ *Corresponding authore-mail address: ezekiel.omotoso@up.ac.za; wmeyer@up.ac.za ; +27842911287
}

\begin{abstract}
We have studied the defects introduced in $n$-type $4 \mathrm{H}-\mathrm{SiC}$ during electron beam deposition (EBD) of tungsten by deep-level transient spectroscopy (DLTS). The results from currentvoltage and capacitance-voltage measurements showed deviations from ideality due to damage, but were still well suited to a DLTS study. We compared the electrical properties of six electrically active defects observed in EBD Schottky barrier diodes with those introduced in resistively evaporated material on the same material, as-grown, as well as after high energy electron irradiation (HEEI). We observed that EBD introduced two electrically active defects with energies $\mathrm{E}_{\mathrm{C}}-0.42$ and $\mathrm{E}_{\mathrm{C}}-0.70 \mathrm{eV}$ in the $4 \mathrm{H}-\mathrm{SiC}$ at and near the interface with the tungsten. The defects introduced by EBD had properties similar to defect attributed to the silicon or carbon vacancy, introduced during HEEI of 4H-SiC. EBD was also responsible for the increase in concentration of a defect attributed to nitrogen impurities $\left(E_{C}-0.10\right)$ as well as a defect linked to the carbon vacancy $\left(\mathrm{E}_{\mathrm{C}}-0.67\right)$. Annealing at $400{ }^{\circ} \mathrm{C}$ in $\mathrm{Ar}$ ambient removed these two defects introduced during the EBD.
\end{abstract}

Keywords: 4H-SiC, defects, DLTS, annealing, electron beam deposition

\section{Introduction}

Metal-semiconductor (M-S) Schottky barrier diodes (SBDs) are widely used where diodes with low forward voltage drop, low capacitance and high switching speed are required [1]. The reliability of the SBDs is influenced significantly by the quality of the M-S junction [2]. The performance of devices can be quantified experimentally in terms of their ideality factor, Schottky barrier height, saturation current, series resistance and free carrier concentration. Among these properties of the M-S devices, SBH plays a major role in the successful operation of many devices in transporting electrons across the M-S junction [3, 4]. 
Silicon carbide (SiC) is a promising semiconductor with a wide bandgap of $3.26 \mathrm{eV}$ [5]. The excellent properties of SiC such as high thermal conductivity, high breakdown field and high saturated drift velocity have drawn the interest of many researchers [6]. These characteristics make $\mathrm{SiC}$ a very good semiconductor capable of outperforming silicon in electronic devices for high-power, high-frequency and high-temperature applications [7]. SiC is a key material for the next-generation photonics [8] and a good candidate for electronic devices used in radiation-harsh environments such as in aerospace, accelerator facilities and nuclear power plants [9-11].

In earlier studies, the properties of deep level defects introduced during alpha-particles irradiation, high-energy electron irradiation (HEEI) and electron beam exposure have been reported [12-14]. It has been reported that metallization processes, such as electron-beam deposition and sputter deposition, introduce electrically active defects in measurable quantities at and close to M-S junction in conventional semiconductors such as $\mathrm{Si}, \mathrm{Ge}$ and GaAs [15-18], and 6H-SiC [19]. The defects introduced influence the performance of devices and may alter the barrier height of metal-semiconductor contacts [20-22]. Deep-level defects responsible for barrier alterations are formed when energetic particles strike the surface of the semiconductor and interact with semiconductor creating interface states, while defects deeper in the semiconductor usually lead to levels in the band gap that trap and emit carriers. Defects may either be beneficial for or detrimental to device performance depending on the application. It has been known that the defects introduced during high-energy electron and proton irradiation of silicon increase in switching speed of devices [23]. To the best of our knowledge, no in-depth investigations regarding the deep level defects introduced in $n$-type $4 \mathrm{H}-\mathrm{SiC}$ during the metallization process has been reported.

In this paper, we report the electronic characteristics of deep level defects introduced in nitrogen-doped, $n$-type $4 \mathrm{H}$-SiC during electron beam deposition (EBD) of W Schottky contacts. The defects introduced by EBD will be compared to the defects introduced after HEEI of $\mathrm{Ni} / 4 \mathrm{H}-\mathrm{SiC}$.

\section{Experimental procedure}

The samples used for this study were cut from homoepitaxially grown, $\mathrm{N}$-doped, $n$-type 4H-SiC wafers supplied by Cree Research Inc. The epilayer was grown by chemical vapour deposition on the Si-face of the SiC substrate, which had a net doping density of $1 \times 10^{18} \mathrm{~cm}^{-3}$ and resistivity of $0.019 \Omega-\mathrm{cm}$. The epilayer had a doping density of $\sim 4 \times 10^{14} \mathrm{~cm}^{-3}$. 
Before metallization, the samples were degreased by boiling for 5 minutes each in trichloroethylene, acetone and methanol, followed by 1 minute rinse in de-ionized water. They were etched in $40 \%$ hydrofluoric acid for 30 seconds in order to remove the native oxide layer on the samples, and then rinsed in de-ionized water followed by blowing dry with nitrogen gas. Directly after cleaning, the samples were inserted into a vacuum chamber where $\mathrm{Ni}$ was resistively evaporated on the highly doped back surfaces to form an ohmic contact. The ohmic contact with a thickness of $300 \mathrm{~nm}$ was deposited at a rate of $\sim 0.1 \mathrm{~nm} . \mathrm{s}^{-1}$. The samples were annealed in a quartz tube heated by a Lindberg Hevi-Duty furnace under flowing argon gas at $950{ }^{\circ} \mathrm{C}$ for 10 minutes to form nickel silicides [24] in order to reduce contact resistance. The samples were cleaned in an ultrasonic water bath for 3 minutes each in trichloroethylene, acetone and methanol followed by a 1 minute rinse in de-ionized $\mathrm{H}_{2} \mathrm{O}$ after the annealing of the ohmic contact [12].

Tungsten contacts, $0.6 \mathrm{~mm}$ in diameter and $40 \mathrm{~nm}$ in thickness, were evaporated in an EBD system through a metal contact mask at a rate of $\sim 0.02 \mathrm{~nm} . \mathrm{s}^{-1}$. The EBD of tungsten was achieved using a $10 \mathrm{kV}$ source (MDC model e-Vap 10CVS) and a beam current of $\sim 240$ $\mathrm{mA}$ with samples placed $\sim 50 \mathrm{~cm}$ away from the $\mathrm{W}$ crucible. A high beam current was required because of the high melting point of $\mathrm{W}\left(3422{ }^{\circ} \mathrm{C}\right)$. The vacuum of $\sim 1.2 \times 10^{-5} \mathrm{mbar}$ was maintained during the deposition.

Ni Schottky contacts of thickness $100 \mathrm{~nm}$ were resistively evaporated (RE) through a metal contact mask on an identical sample at a deposition rate of $0.05 \mathrm{~nm} . \mathrm{s}^{-1}$ under a vacuum of $5.0 \times 10^{-5}$ mbar, which served as a "control".

In addition, the control samples were irradiated at room temperature with high-energy electrons from a ${ }^{90} \mathrm{Sr}$ radioactive source for 24 hours at fluence rate of $7 \times 10^{9} \mathrm{~cm}^{-2} \cdot \mathrm{s}^{-1}$. The total fluence received by SBDs was $6 \times 10^{14} \mathrm{~cm}^{-2}$. The $\mathrm{Sr}$ electron source used was discshaped with a diameter of $8.4 \mathrm{~mm}$ and an activity of $20 \mathrm{mCi}$. The ${ }^{90} \mathrm{Sr}$ radionuclide (half-life of 28.5 years) decays first to yttrium (half-life of 64.1 hours) with the emission of a $0.5 \mathrm{MeV}$ electron. The yttrium then decays by the emission of a $2.27 \mathrm{MeV}$ electron to zirconium. The emitted electrons from the electron source have a continuous energy distribution with approximately $\sim 70 \%$ of the total number of emitted electrons having energy above $0.25 \mathrm{MeV}$ [25].

The electrical properties of devices fabricated by EBD were characterized at room temperature using a current-voltage $(I-V)$ and capacitance-voltage $(C-V)$ system comprising an HP 4140 B pA Meter/DC Voltage Source and an HP 4192A LF Impedance Analyzer, respectively. Thereafter, electrically active defects were characterized by deep level transient 
spectroscopy (DLTS), a set-up made up of a closed cycle helium cryostat and a Boonton 7200 capacitance meter with $100 \mathrm{mV}$ and $1 \mathrm{MHz}$ test signal. The SBDs fabricated by EBD were annealed in an Ar ambient at the interval of $100{ }^{\circ} \mathrm{C}$ for 20 minutes to know the stability of the defects introduced during metallization.

\section{Results and discussion}

The suitability of the devices fabricated by EBD and the control by RE before and after HEEI for this study was tested by $I-V$ and $C-V$ measurements. The forward $I-V$ characteristics of W Schottky contacts deposited by EBD, and the control by RE before and after HEEI are shown in Fig. 1. A thermionic emission model was used to analyse the $I-V$ characteristics of the EBD of W/4H-SiC and $\mathrm{RE}$ of $\mathrm{Ni} / 4 \mathrm{H}-\mathrm{SiC}$ SBDs before and after HEEI.

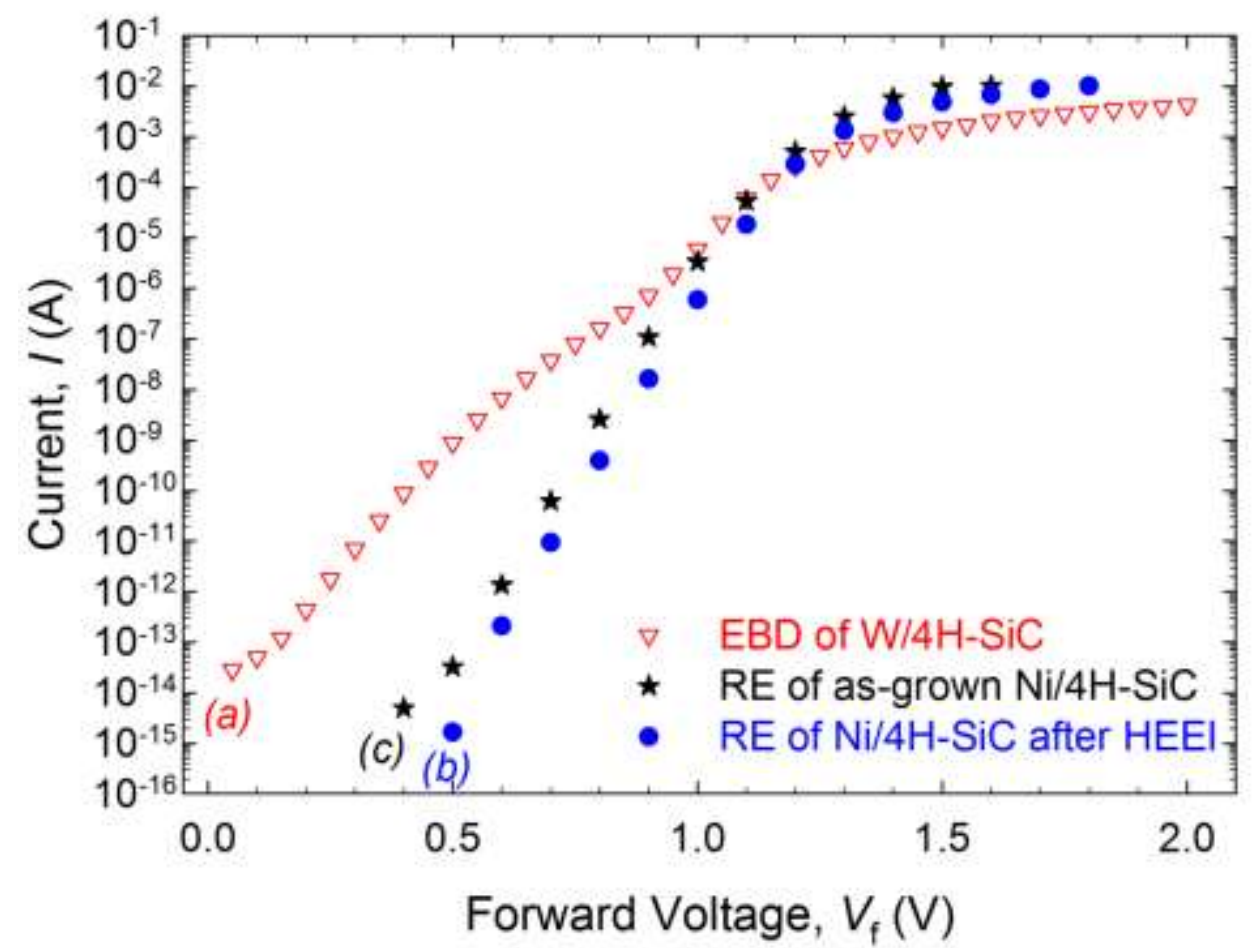

Fig. 1: The $I-V$ characteristics of W Schottky contact on $4 \mathrm{H}-\mathrm{SiC}$ deposited by EBD and RE of Ni/4H-SiC before and after HEEI.

From plot (a) in Fig. 1, it was deduced that thermionic emission dominated above $\sim 0.55 \mathrm{~V}$, measured at $300 \mathrm{~K}$ in the dark. At lower voltages (below $0.55 \mathrm{~V}$ ), generationrecombination dominated. The presence of two regions in the forward bias $I-V$ plot of (a) occurred as a result of deep-level defects that degrade the device. The saturation of the current in the high voltage region of Fig. 1 is due to the series resistance. The electrical parameters that were extracted from $I-V$ and $C-V$ characteristics are tabulated in Table 1 . The 
parameters for $I-V$ and $C-V$ were determined as reported earlier by Omotoso et al.[13, 26]. From the results, a high value of ideality factor $n$ was observed and was attributed to deviation from thermionic emission theory. The $I-V$ Schottky barrier height $\phi_{\mathrm{I}-\mathrm{V}}$ obtained from the plot was $0.98 \mathrm{eV}$, which is slightly lower than the predicted value by the Schottky model $\left(\chi=\phi_{\mathrm{M}}-\chi=1.40 \mathrm{eV}\right)$, which indicates the influence of interface states. It can be deduced from the value of $n, I_{\mathrm{s}}, R_{\mathrm{s}}$ and $\phi_{\mathrm{I}-\mathrm{V}}$ in Table 1 that EBD degraded the Schottky contacts.

Table 1: Electrical parameters obtained from $I-V$ and $C-V$ of EBD of $\mathrm{W} / 4 \mathrm{H}-\mathrm{SiC}$ (a), and $\mathrm{RE}$ of Ni/4H-SiC before (b) and HEEI (c).

\begin{tabular}{cccccccc}
\hline & $n$ & $I_{\mathrm{S}}(\mathrm{A})$ & $R_{\mathrm{S}}(\Omega)$ & $V_{\mathrm{bi}}(\mathrm{V})$ & $N_{\mathrm{d}}\left(\mathrm{cm}^{-3}\right)$ & $\phi_{\mathrm{I}-\mathrm{V}}(\mathrm{eV})$ & $\phi_{\mathrm{C}-\mathrm{V}}(\mathrm{eV})$ \\
\hline (a) & 2.50 & $6.2 \times 10^{-13}$ & 158 & 1.34 & $5.4 \times 10^{14}$ & 0.98 & 1.68 \\
(b) & 1.04 & $2.3 \times 10^{-22}$ & 29 & 1.58 & $5.9 \times 10^{14}$ & 1.53 & 1.92 \\
(c) & 1.07 & $6.6 \times 10^{-23}$ & 48 & 1.64 & $6.4 \times 10^{14}$ & 1.56 & 1.98 \\
\hline
\end{tabular}

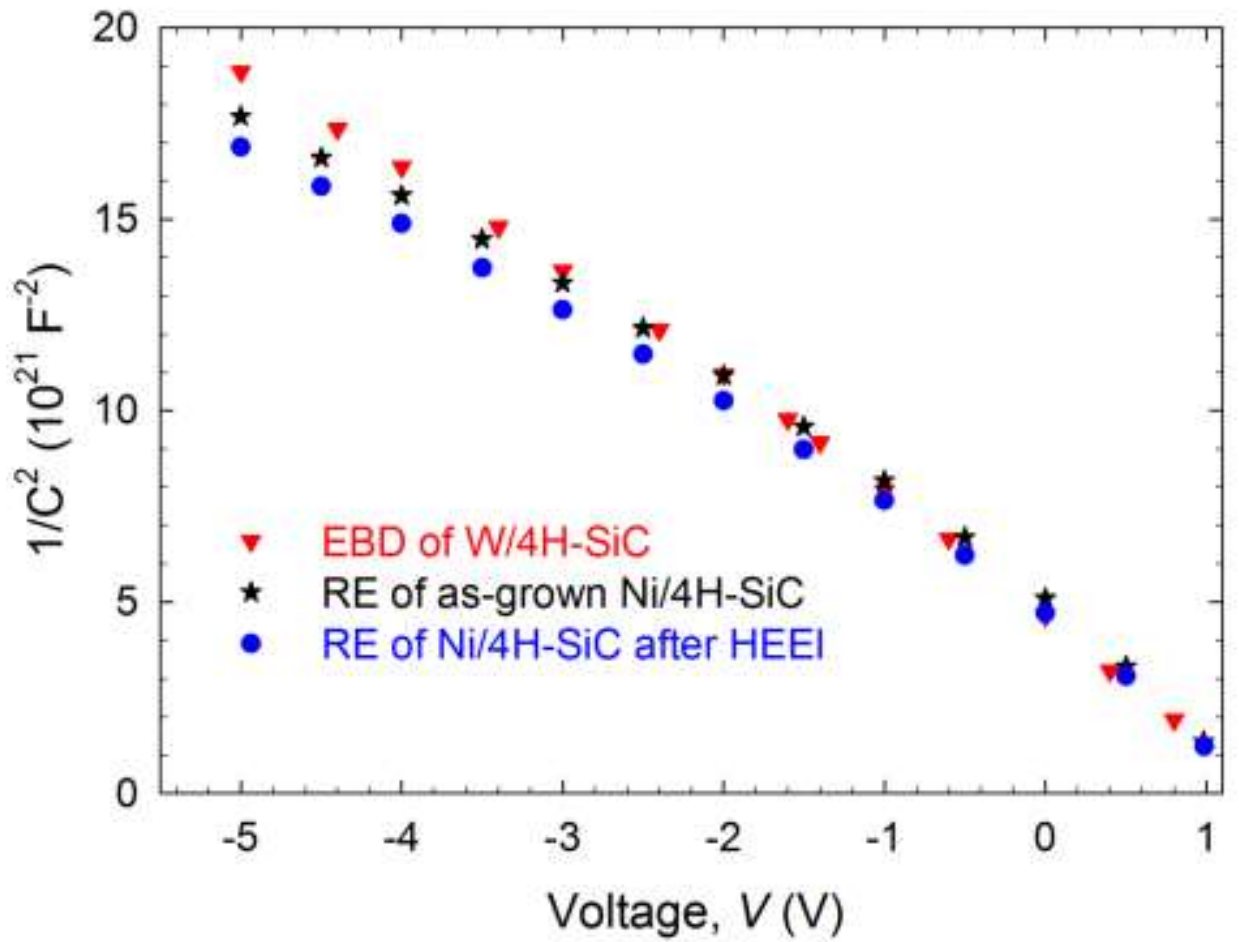

Fig. 2: $1 / C^{2}$ as a function of voltage for W Schottky contact on $4 \mathrm{H}-\mathrm{SiC}$ deposited by $\mathrm{EBD}$ and $\mathrm{RE}$ of Ni/4H-SiC before and after HEEI.

Fig. 2 shows the plots of $C^{-2}$ as a function of bias voltage, $V$ for EBD of W/4H-SiC and $\mathrm{RE}$ of Ni/4H-SiC SBDs before and after HEEI. The carrier concentrations of the EBD sample and the control were determined and tabulated in Table 1. An increasing negative slope of the graph towards the interface is an indication of a decreased net doping density close to the interface. Fig. 3 shows the $C-V$ depth profiling for the EBD and the control 
diodes. It was deduced from the plot that the effect of EBD on the diodes is close to the surface of Ni-4H-SiC junction. The $\phi_{\mathrm{C}-\mathrm{V}}(1.68 \mathrm{eV})$ obtained was greater the $\phi_{\mathrm{I}-\mathrm{V}}(0.98 \mathrm{eV})$ which is probably due to deep impurity levels, but may also be due to surface inhomogeneity, interfacial layer or states, image force barrier lowering and edge leakage current [27].

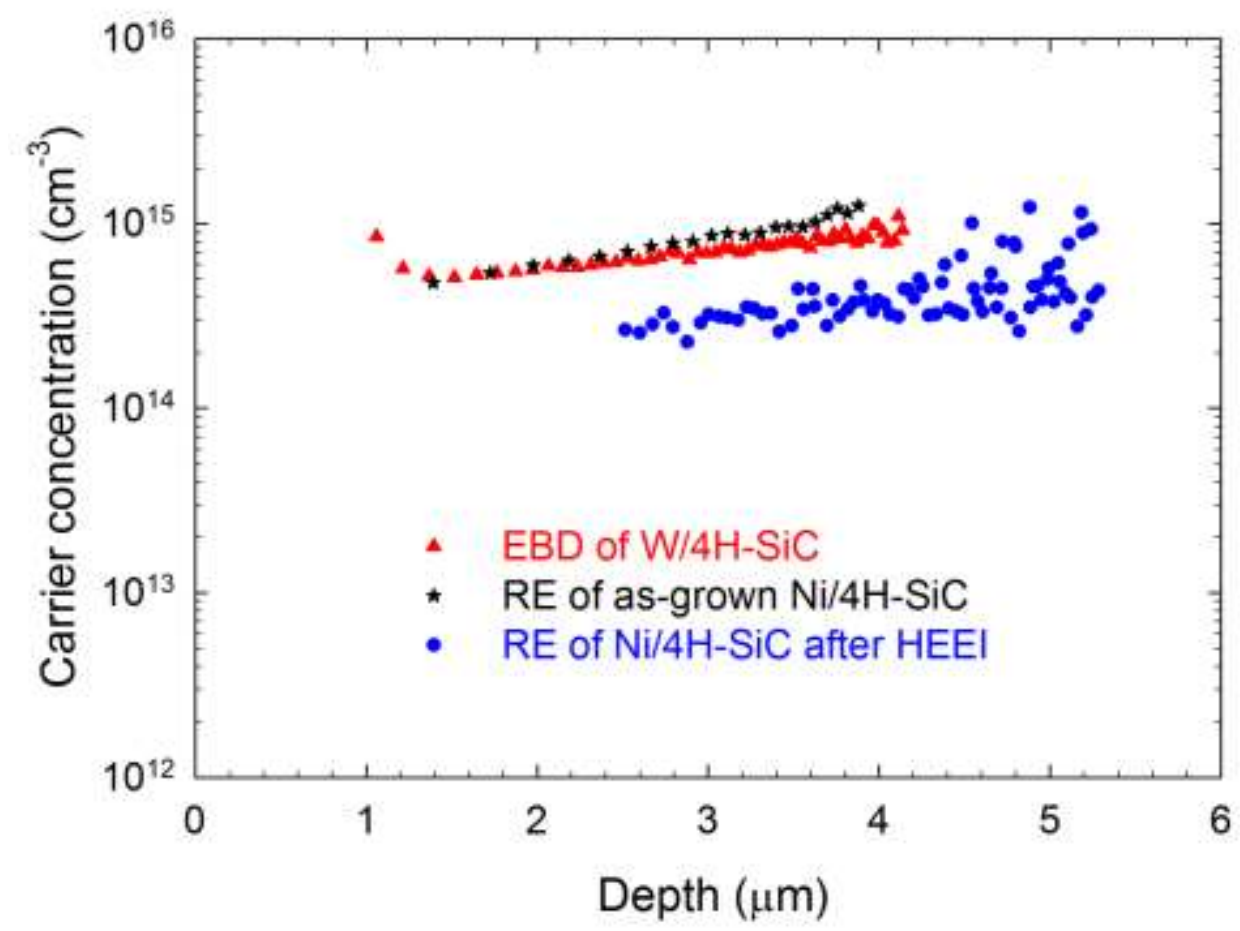

Fig. 3: The $C-V$ depth profiling of EBD of W/4H-SiC and the control (RE of Ni/4H-SiC) before and after HEEI.

The $I-V$ and $C-V$ characteristics of the control SBDs before and after HEEI were shown in Figs. 1 and 2 for completeness, but not compared to the SBDs by EBD because metals influence the electrical characteristics of devices.

From the results of both $I-V$ and $C-V$ characteristics obtained, it is apparent that the rectification quality of the control and EBD SBDs were of a reasonable electrical quality and were suitable for the analysis of DLTS study. 


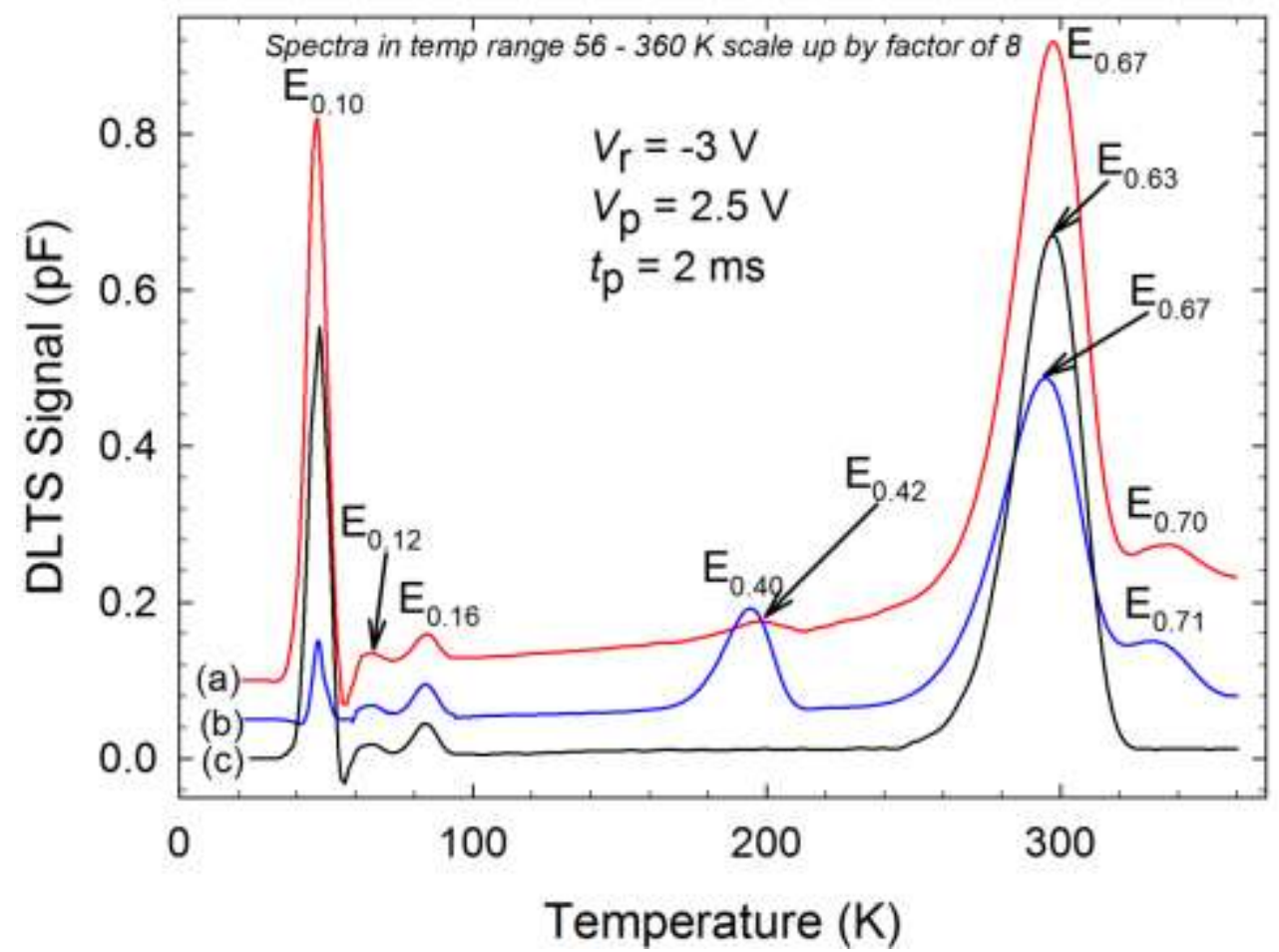

Fig. 4: Conventional DLTS spectra of W/4H-SiC deposited by EBD (a), Ni/4H-SiC deposited by RE after HEEI (b) and as-grown (c). The spectra in the temperature range 56-360 K are scaled up by a factor of 8. The DLTS measurements were obtained at a quiescent reverse bias of $-3.0 \mathrm{~V}$, filling pulse of amplitude $-0.5 \mathrm{~V}$, width of $2.0 \mathrm{~ms}$ and at rate window of $10 \mathrm{~s}^{-1}$.

Figs. 4 and 5 depict the DLTS spectra of EBD of W/4H-SiC (a), RE deposition of $\mathrm{Ni} / 4 \mathrm{H}-\mathrm{SiC}$ after HEEI (b), and control RE deposition of Ni/4H-SiC (c). The DLTS spectra in Fig. 4 were obtained over the temperature range $22-360 \mathrm{~K}$, at a quiescent reverse bias of $-3.0 \mathrm{~V}$, filling pulse of amplitude $-0.5 \mathrm{~V}$, width of $2.0 \mathrm{~ms}$ and at rate window of $10 \mathrm{~s}^{-1}$. Fig. 5 was obtained with the same conditions except with the quiescent reverse bias of $-5.0 \mathrm{~V}$ and filling pulse of amplitude $4.0 \mathrm{~V}$. The signatures of the electrically active defects present, namely their activation energy $\mathrm{E}_{\mathrm{n}}$ and apparent capture cross section $\sigma_{\mathrm{n}}$ were determined from Arrhenius plots in Fig. 6. The activation energy of each defect was determined from the slope and the corresponding apparent capture cross section was calculated from the intercept of the Arrhenius plot of $\log \left(T^{2} / e_{\mathrm{n}}\right)$ versus $1 / T[28]$. 


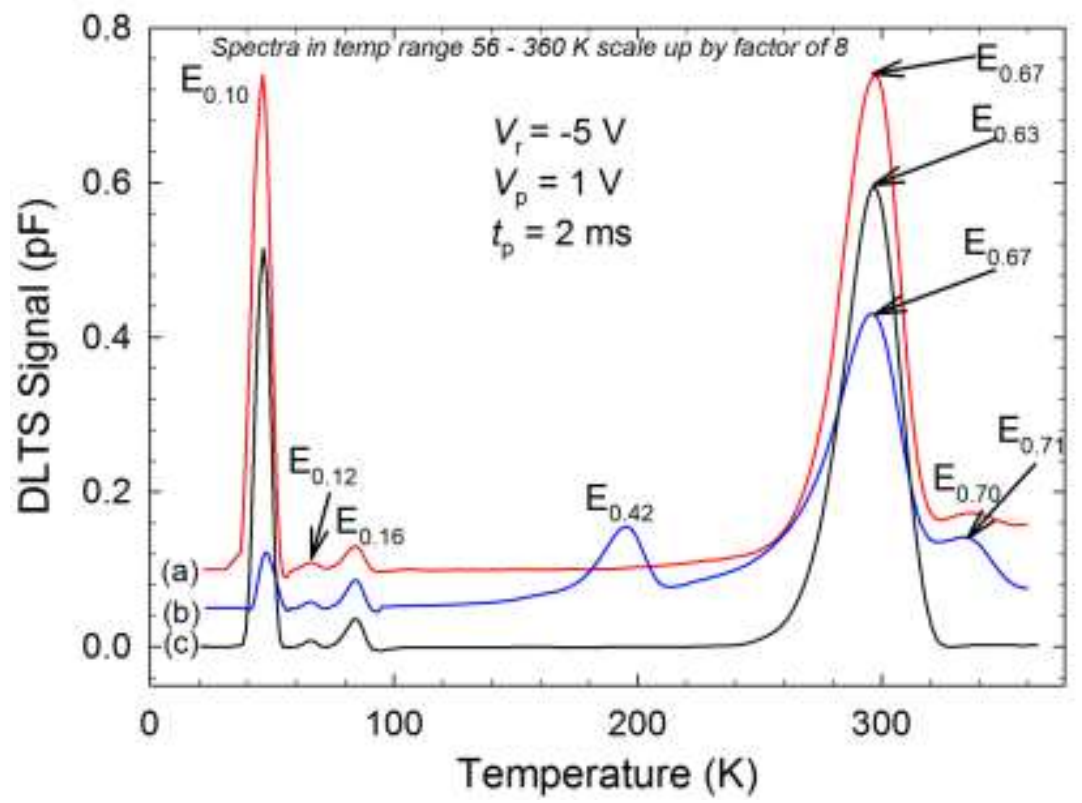

Fig. 5: Conventional DLTS spectra of W/4H-SiC deposited by EBD (a), Ni/4H-SiC deposited by RE after HEEI (b) and as-grown (c). The spectra in the temperature range $56-360 \mathrm{~K}$ are scaled up by actor of 8 . The measurements were obtained at a quiescent reverse bias of $-5.0 \mathrm{~V}$, filling pulse of amplitude $4.0 \mathrm{~V}$, width of 2.0 $\mathrm{ms}$ and at rate window of $10 \mathrm{~s}^{-1}$.

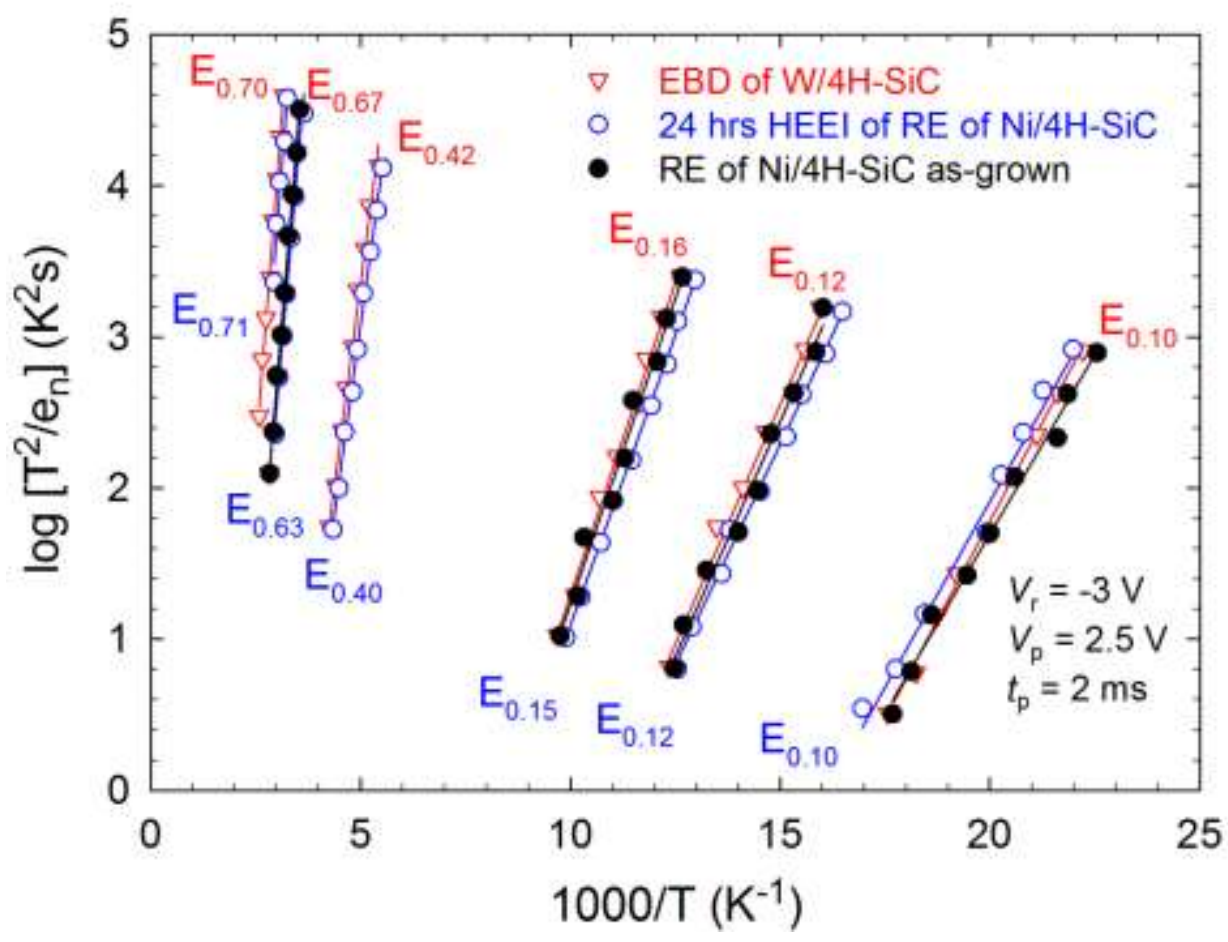

Fig. 6: Arrhenius plots of electrically active deep-level defects in EBD of W/4H-SiC and $\mathrm{RE}$ of $\mathrm{Ni} / 4 \mathrm{H}-\mathrm{SiC}$ SBDs before and after HEEI. The measurements were obtained at a quiescent reverse bias of $-3.0 \mathrm{~V}$, filling pulse of amplitude $-0.5 \mathrm{~V}$, width of $2.0 \mathrm{~ms}$ and at multi-rate windows. 
The spectra (c) in Figs. 4 and 5 revealed the presence of four electron deep levels labelled $\mathrm{E}_{0.10}, \mathrm{E}_{0.12}, \mathrm{E}_{0.16}$ and $\mathrm{E}_{0.67}$ (where ' $\mathrm{E}$ ' refers to an electron trap and the subscript refers to the energy level below the conduction band in $\mathrm{eV}$ ) in the as-grown $\mathrm{Ni} / 4 \mathrm{H}-\mathrm{SiC}$ SBDs. These levels were studied previously $[12,13,29]$. The conclusions related to these and other defects are summarised in Table 2.

Table 2: Electronic properties of defects introduced in $n$-type 4H-SiC during EBD of $\mathrm{W}$ and RE of Ni before and after HEEI.

\begin{tabular}{lccccc}
\hline Process & Defect label & $E_{\mathrm{T}}(\mathrm{eV})$ & $\sigma_{\mathrm{a}}\left(\mathrm{cm}^{2}\right)$ & Defect ID & References \\
\hline $\begin{array}{l}\text { Electron-beam } \\
\text { deposition }\end{array}$ & $\mathrm{E}_{0.10}$ & $E_{\mathrm{C}}-0.10$ & $1.4 \times 10^{-13}$ & $\mathrm{~N}$ & {$[30]$} \\
(EBD) & $\mathrm{E}_{0.12}$ & $E_{\mathrm{C}}-0.12$ & $2.7 \times 10^{-15}$ & $\mathrm{Ti}$ & {$[32]$} \\
& $\mathrm{E}_{0.16}$ & $E_{\mathrm{C}}-0.16$ & $2.9 \times 10^{-15}$ & $\mathrm{Ti}$ & {$[33]$} \\
& $\mathrm{E}_{0.42}$ & $E_{\mathrm{C}}-0.42$ & $6.3 \times 10^{-15}$ & $\mathrm{~V}_{\mathrm{C} / \mathrm{Si}}$ & {$[34]$} \\
& $\mathrm{E}_{0.67}$ & $E_{\mathrm{C}}-0.67$ & $9.9 \times 10^{-15}$ & $\mathrm{Z}_{1} / \mathrm{Z}_{2}\left(\mathrm{~V}_{\mathrm{C}}\right)$ & {$[35]$} \\
& $\mathrm{E}_{0.70}$ & $E_{\mathrm{C}}-0.70$ & $1.2 \times 10^{-15}$ & $?$ & \\
\hline Resistive & $\mathrm{E}_{0.10}$ & $E_{\mathrm{C}}-0.10$ & $2.8 \times 10^{-14}$ & $\mathrm{~N}$ & {$[30]$} \\
(RE) & $\mathrm{E}_{0.12}$ & $\mathrm{E}_{\mathrm{C}}-0.12$ & $2.2 \times 10^{-15}$ & $\mathrm{Ti}$ & {$[32]$} \\
& $\mathrm{E}_{0.16}$ & $\mathrm{E}_{\mathrm{C}}-0.16$ & $2.1 \times 10^{-15}$ & $\mathrm{Ti}$ & {$[33]$} \\
\hline $\begin{array}{l}\text { High-energy } \\
\text { electron }\end{array}$ & $\mathrm{E}_{0.67}$ & $\mathrm{E}_{\mathrm{C}}-0.67$ & $7.0 \times 10^{-15}$ & $\mathrm{Z}_{1} / \mathrm{Z}_{2}\left(\mathrm{~V}_{\mathrm{C}}\right)$ & {$[35]$} \\
irradiation & $\mathrm{E}_{0.10}$ & $E_{\mathrm{C}}-0.10$ & $2.6 \times 10^{-14}$ & $\mathrm{~N}$ & {$[30]$} \\
(HEEI) & $\mathrm{E}_{0.12}$ & $E_{\mathrm{C}}-0.12$ & $8.4 \times 10^{-16}$ & $\mathrm{Ti}$ & {$[32]$} \\
& $\mathrm{E}_{0.15}$ & $E_{\mathrm{C}}-0.15$ & $1.2 \times 10^{-15}$ & $\mathrm{Ti}$ & {$[33]$} \\
& $\mathrm{E}_{0.40}$ & $E_{\mathrm{C}}-0.40$ & $3.0 \times 10^{-15}$ & $\mathrm{~V}_{\mathrm{C} / \mathrm{Si}}$ & {$[34]$} \\
& $\mathrm{E}_{0.63}$ & $E_{\mathrm{C}}-0.63$ & $3.0 \times 10^{-15}$ & $\mathrm{Z}_{1} / \mathrm{Z}_{2}\left(\mathrm{~V}_{\mathrm{C}}\right)$ & {$[35]$} \\
& $\mathrm{E}_{0.71}$ & $E_{\mathrm{C}}-0.71$ & $2.7 \times 10^{-15}$ & $?$ & $?$ \\
\hline
\end{tabular}

The spectra (b) revealed the presence of six electrically active electron defects after bombarding the Ni/4H-SiC SBDs with high-energy electron. The defects were labelled $\mathrm{E}_{0.10}$, $\mathrm{E}_{0.12}, \mathrm{E}_{0.15}, \mathrm{E}_{0.40}, \mathrm{E}_{0.63}$ and $\mathrm{E}_{0.71}$, following the same naming convention as earlier. From the defect signatures as tabulated in Table 2, two of these defects $\left(\mathrm{E}_{0.42}\right.$ and $\left.\mathrm{E}_{0.71}\right)$ were introduced by HEEI while the other four defects $\left(\mathrm{E}_{0.10}, \mathrm{E}_{0.12}, \mathrm{E}_{0.15}\right.$, and $\left.\mathrm{E}_{0.63}\right)$ were present in the as-grown diodes. The concentration of defects $\mathrm{E}_{0.10}$ and $\mathrm{E}_{0.63}$ decreased by $\sim 82 \%$ and $\sim 35 \%$, respectively, after the HEEI. The activation energy of $\mathrm{E}_{0.63}$ reduced from $0.67 \mathrm{eV}$ to $0.63 \mathrm{eV}$, but still within the experimental error. These defects $\left(\mathrm{E}_{0.10}\right.$ and $\left.\mathrm{E}_{0.63}\right)$ were attributed to nitrogen impurities and carbon vacancies, respectively. We believe that the decrease in the relatively shallow $\mathrm{E}_{0.10}$, which is ascribed to nitrogen impurities [30], was due to a lowering of the Fermi level because of deep levels in the band gap. The decrease in the $\mathrm{E}_{0.63}$, which is 
ascribed to the carbon vacancy, could be due to some of the vacancies being filled by diffusing interstitials. It is noteworthy that despite the changes in DLTS biasing conditions as revealed in spectra in Figs. 4 and 5, there was insignificant change in the concentration of the defects.

The EBD spectra of W/4H-SiC SBDs for both measurement conditions are labelled (a) in Figs. 4 and 5. From Fig. 4, six electron deep level defects were present in the W/4HSiC SBDs deposited by EBD when measured at a quiescent reverse bias of $-3.0 \mathrm{~V}$, filling pulse of amplitude $-0.5 \mathrm{~V}$. The defects were also labelled as $\mathrm{E}_{0.10}, \mathrm{E}_{0.12}, \mathrm{E}_{0.16}, \mathrm{E}_{0.42}, \mathrm{E}_{0.67}$ and $\mathrm{E}_{0.70}$, with four defects $\left(\mathrm{E}_{0.10}, \mathrm{E}_{0.12}, \mathrm{E}_{0.16}\right.$ and $\left.\mathrm{E}_{0.67}\right)$ corresponding to defects that have been observed in RE Ni/4H-SiC SBDs. The two defects $\left(\mathrm{E}_{0.42}\right.$ and $\left.\mathrm{E}_{0.70}\right)$ were introduced as a result of metallization by EBD. The DLTS spectrum of EBD W/4H-SiC SBDs measured at a quiescent reverse bias of $-5.0 \mathrm{~V}$ and filling pulse of amplitude $4.0 \mathrm{~V}$ (Fig. 5(a)) sampled a broader depth range under the contact, and revealed the presence of five electrically active defects. This included all the defects observed previously except $\mathrm{E}_{0.42}$. This defect $\mathrm{E}_{0.42}$ is characterized by a skewed baseline of which the offset increases with increasing in temperature. It is important to point out that defects introduced by EBD were at or close to the W/4H-SiC interface which can be supported by $C-V$ depth profiling shown in Fig. 3. The skewed baseline also supported the closeness of $\mathrm{E}_{0.42}$ to interface with a continuous energy distribution of which the concentration increases with depth below the conduction band, as reported by ref. [31].

By comparing spectra (b) and (c) in Fig. 4, it seems that HEEI reduced the peak height of $\mathrm{E}_{0.67}$ slightly and that of $\mathrm{E}_{0.10}$ significantly, while increasing the peak height due to $\mathrm{E}_{0.42}$. By comparing (a) to the other two spectra, it is clear that $\mathrm{E}_{0.42}$ was much less pronounced in (a) than in (b). This can be used to explain the lesser reduction of $E_{0.10}$ in (b) compared to (a), if it is assumed that both processes introduce defects in roughly the same ratios. At first glance, the height of the $\mathrm{E}_{0.67}$ seems to be higher in (a) than in (b). However, if the skewed baseline of (a) is taken into account, the peak heights are very similar and no definite conclusions can be drawn. This is also the case for the spectra in Fig. 5. On both (a) and (b) spectra, the $E_{0.70}$ peaks seem to have approximately the same size, it is therefore concluded that $\mathrm{E}_{0.70}$ is introduced in relatively greater proportions by HEEI than EBD. The decrease in the peak heights of $\mathrm{E}_{0.42}$ and $\mathrm{E}_{0.70}$ in the EBD material with larger reverse bias demonstrates the limited depth range of the EBD defects.

The structure of the electrically active defects introduced after EBD of W/4H-SiC SBD were identified by comparing them with the defects present after HEEI of $\mathrm{Ni} / 4 \mathrm{H}-\mathrm{SiC}$ 
$\mathrm{SBD}$, of which the structures have previously been identified except $\mathrm{E}_{0.70 / 0.71}$. The attribution of the electrically active defects observed in this study has been tabulated in Table 2 .

Finally, the thermal stability of EBD induced defects in W/4H-SiC was investigated. No noticeable changes were observed after annealing at $100{ }^{\circ} \mathrm{C}$ for 20 minutes. The concentration of defects labelled $\mathrm{E}_{0.42}$ and $\mathrm{E}_{0.70}$ started decreasing after the annealing at 200 ${ }^{\circ} \mathrm{C}$. After the annealing at $400{ }^{\circ} \mathrm{C}$, the two electrically active deep levels associated with EBD were removed completely after approximately 20 minutes. The ideality factor of the EBD SBD was improved after the annealing at $400{ }^{\circ} \mathrm{C}$.

\section{Conclusions}

The quality of EBD of $\mathrm{W}$ on $n$-type 4H-SiC SBDs for DLTS has been investigated by $I-V$ and $C-V$ measurements. The $I-V$ and $C-V$ measurements of EBD diodes showed that EBD resulted in the degradation of the device due to the presence of deep-level defects introduced during the deposition. However these diodes were still suitable for the DLTS study. DLTS of the EBD deposited diodes revealed the presence of six electrically active defects with energies $0.10,0.12,0.16,0.42,0.67$ and $0.70 \mathrm{eV}$ below the conduction band minimum in EBD SBDs. Closely comparing these defects with defects present in the as-grown $\mathrm{Ni} / 4 \mathrm{H}-\mathrm{SiC}$ SBDs and after bombardment with high-energy electron revealed that EBD introduced two electrically active deep-level defects $\left(\mathrm{E}_{0.42}\right.$ and $\left.\mathrm{E}_{0.70}\right)$ that have the same electronic properties as defects introduced by HEEI. These two electrically active defects with energies, $E_{\mathrm{C}}-0.42$ and $E_{\mathrm{C}}-0.70 \mathrm{eV}$, possibly introduced as a result of the product of elastic collisions between $10 \mathrm{keV}$ electrons and residual vacuum gases which were ionized around the filament and accelerated by the electric field towards the substrate. The two electrically active deep levels were removed after the annealing at $400{ }^{\circ} \mathrm{C}$ in Ar.

\section{Acknowledgements}

This work is based on the research supported in part by the National Research Foundation (NRF) of South African (Grant specific unique reference number (UID) 78838). The Grant holder acknowledges that opinions, findings and conclusions or recommendations expressed in this publication generated by the NRF supported are that of authors and that NRF accepts no liability whatsoever in this regard. 


\section{References}

[1] R.L. Van Tuyl, C.A. Liechti, IEEE Journal of Solid-State Circuits, , 9 (1974) 269-276.

[2] E. Rhoderick, R. Williams, Oxford Science, Oxford, 1988.

[3] V. Janardhanam, A. Ashok Kumar, V. Rajagopal Reddy, P. Narasimha Reddy, Journal of Alloys and Compounds, 485 (2009) 467-472.

[4] C. Persson, U. Lindefelt, Physical Review B, 54 (1996) 10257-10260.

[5] L.M. Tolbert, B. Ozpineci, S.K. Islam, M.S. Chinthavali, Power and Energy Systems, Proceedings, 1 (2003) 317-321.

[6] M. Siad, M. Abdesslam, A.C. Chami, Applied Surface Science, 258 (2012) 6819-6822.

[7] R. Madar, Nature, 430 (2004) 974-975.

[8] S. Yamada, B.-S. Song, T. Asano, S. Noda, Applied Physics Letters, 99 (2011) 2011021-2011023.

[9] T. Nishijima, T. Ohshima, K.K. Lee, Nuclear Instruments and Methods in Physics Research Section B: Beam Interactions with Materials and Atoms, 190 (2002) 329-334.

[10] F. Nava, E. Vittone, P. Vanni, G. Verzellesi, P.G. Fuochi, C. Lanzieri, M. Glaser, Nuclear Instruments and Methods in Physics Research Section A: Accelerators, Spectrometers, Detectors and Associated Equipment, 505 (2003) 645-655.

[11] L. Kin Kiong, T. Ohshima, H. Itoh, Nuclear Science, IEEE Transactions on, 50 (2003) 194-200.

[12] E. Omotoso, W.E. Meyer, F.D. Auret, A.T. Paradzah, M. Diale, S.M.M. Coelho, P.J. Janse van Rensburg, P.N.M. Ngoepe, Nuclear Instruments and Methods in Physics Research Section B: Beam Interactions with Materials and Atoms, (2015) 5.

[13] E. Omotoso, W.E. Meyer, F.D. Auret, A.T. Paradzah, M. Diale, S.M.M. Coelho, P.J. Janse van Rensburg, Materials Science in Semiconductor Processing, 39 (2015) 112-118.

[14] E. Omotoso, W.E. Meyer, F.D. Auret, S.M. Martins Coelho, P.N.M. Ngoepe, Solid State Phenomena, Trans Tech Publ, 2015, pp. 427-433.

[15] F. Auret, W. Barnard, G. Myburg, L. Bredell, South African Journal Science, 87 (1991) 127-129.

[16] F.D. Auret, S.M.M. Coelho, J.M. Nel, W.E. Meyer, Physica Status Solidi (A), 209 (2012) 1926-1933.

[17] F.D. Auret, W.E. Meyer, S. Coelho, M. Hayes, Applied Physics Letters, 88 (2006) 242110. 
[18] S.M.M. Coelho, F.D. Auret, P.J. Janse van Rensburg, J.M. Nel, Journal of Applied Physics, 114 (2013) 1737081-1737088.

[19] E. van Wyk, A. Leitch, Semiconductor science and technology, 19 (2004) 610.

[20] F.D. Auret, O. Paz, N.A. Bojarczuk, Journal of Applied Physics, 55 (1984) 1581-1589.

[21] F.D. Auret, S.A. Goodman, F.K. Koschnick, J.-M. Spaeth, B. Beaumont, P. Gibart, Applied Physics Letters, 74 (1999) 2173-2175.

[22] G. Myburg, F. Auret, Journal of Applied Physics, 71 (1992) 6172-6176.

[23] D.C. Sawko, J. Bartko, Nuclear Science, IEEE Transactions on, 30 (1983) 1756-1758.

[24] T. Marinova, A. Kakanakova-Georgieva, V. Krastev, R. Kakanakov, M. Neshev, L. Kassamakova, O. Noblanc, C. Arnodo, S. Cassette, C. Brylinski, B. Pecz, G. Radnoczi, G. Vincze, Materials Science and Engineering: B, 46 (1997) 223-226.

[25] F. Auret, S. Goodman, G. Myburg, W. Meyer, Appl. Phys. A, 56 (1993) 547-553.

[26] E. Omotoso, W.E. Meyer, F.D. Auret, A.T. Paradzah, M. Diale, S.M.M. Coelho, P.J. Janse van Rensburg, P.N.M. Ngoepe, Nuclear Instruments and Methods in Physics Research Section B: Beam Interactions with Materials and Atoms, 365, Part A (2015) 264-268.

[27] C.R. Crowell, Solid-State Electronics, 20 (1977) 171-175.

[28] F.D. Auret, P.N.K. Deenapanray, Critical Reviews in Solid State and Materials Sciences, 29 (2004) 1-44.

[29] A.T. Paradzah, F.D. Auret, M.J. Legodi, E. Omotoso, M. Diale, Nuclear Instruments and Methods in Physics Research Section B: Beam Interactions with Materials and Atoms, 358 (2015) 112-116.

[30] T. Kimoto, A. Itoh, H. Matsunami, S. Sridhara, L. Clemen, R. Devaty, W. Choyke, T. Dalibor, C. Peppermüller, G. Pensl, Applied Physics Letters, 67 (1995) 2833-2835.

[31] M.O. Manasreh, III-Nitride Semiconductors: Electrical, Structural and Defects Properties: Electrical, Structural and Defects Properties, Elsevier, 2000.

[32] A.A. Lebedev, Semiconductors, 33 (1999) 107-130.

[33] T. Dalibor, G. Pensl, H. Matsunami, T. Kimoto, W. Choyke, A. Schöner, N. Nordell, Physica Status Solidi (A), 162 (1997) 199-225.

[34] J. Doyle, M.K. Linnarsson, P. Pellegrino, N. Keskitalo, B. Svensson, A. Schoner, N. Nordell, J. Lindstrom, Journal of Applied Physics, 84 (1998) 1354-1357.

[35] N.T. Son, X.T. Trinh, L.S. Løvlie, B.G. Svensson, K. Kawahara, J. Suda, T. Kimoto, T. Umeda, J. Isoya, T. Makino, T. Ohshima, E. Janzén, Physical Review Letters, 109 (2012) 187603. 